\title{
Air pollution and mortality in the Netherlands: are the elderly more at risk?
}

\author{
P. Fischer*, G. Hoek", B. Brunekreef", A. Verhoeff", J. van Wijnen ${ }^{+}$
}

Air pollution and mortality in the Netherlands: are the elderly more at risk? P. Fischer, G. Hoek, B. Brunekreef, A. Verhoeff, J. van Wijnen. (C)ERS Journals Ltd 2003. ABSTRACT: The association between daily mortality and short-term variations in the ambient levels of ozone $\left(\mathrm{O}_{3}\right)$, black smoke $(\mathrm{BS})$, sulphur dioxide $\left(\mathrm{SO}_{2}\right)$, nitrogen dioxide $\left(\mathrm{NO}_{2}\right)$, carbon monoxide $(\mathrm{CO})$ and particulate matter was studied in the Netherlands.

Daily total and cause-specific mortality counts (cardiovascular, chronic obstructive pulmonary disease (COPD) and pneumonia), air quality, temperature, relative humidity and influenza data were obtained from 1986-1994. The relationship between daily mortality and air pollution was modelled using Poisson regression analysis. All pollution mortality associations were adjusted for potential confounding due to longterm trends, seasonal trends, influenza epidemics, ambient temperature, ambient relative humidity, day of the week and holidays, using generalised additive models.

Statistically significant associations were mostly found in the elderly, that is the age categories of 65-74 and $\geqslant 75$ yrs for the pollutants PM10 (particles with a 50\% cut-off aerodynamic diameter of $10 \mu \mathrm{m}), \mathrm{BS}, \mathrm{SO}_{2}, \mathrm{NO}_{2}$ and $\mathrm{CO}$. This may partly be due to a better precision of relative risk (RR) estimates for the larger numbers of deaths in these age groups. Significant associations for those $<65$ yrs were found for $\mathrm{O}_{3}$ (total and COPD mortality), PM10 (pneumonia), $\mathrm{NO}_{2}$ (pneumonia) and $\mathrm{CO}$ (pneumonia).

RR estimates for deaths between $45-65$ yrs tended to be smaller than those in $>65$ yrs, with the exception of ozone; for cardiovascular mortality the RR for PM10, $\mathrm{O}_{3}$ and $\mathrm{CO}$ were similar in these age groups.

In conclusion, larger relative risks for air pollution were mostly found in the elderly except for ozone and for death-cause pneumonia which showed larger relative risk in younger age groups.

Eur Respir J 2003; 21: Suppl. 40, 34s-38s.
*National Institute of Public Health and the Environment, Centre for Environmental Health Research, Bilthoven, ${ }^{\#}$ Environmental and Occupational Health Group, Institute for Risk Assessment Sciences, University of Utrecht, Utrecht, "Municipal Health Service Amsterdam, Dept of Epidemiology and Health Promotion, Amsterdam, ${ }^{+}$Municipal Health Service Amsterdam, Environmental Medicine, Amsterdam, the Netherlands.

Correspondence: P. Fischer, National Institute of Public Health and the Environment, Centre for Environmental Health Research, P.O. Box 1, 3720 Bilthoven, the Netherlands.

Fax: 31302744451

E-mail: p.fischer@rivm.nl

Keywords: Air pollutants elderly

mortality

particles

time series

Received and accepted: April 122002
Associations between outdoor air pollution and effects on both acute and chronic mortality and hospital admissions in the Netherlands have been published recently. VERHOEFF et al. [1] studied the association between fluctuations in daily mortality and daily levels of ambient air pollution for the city of Amsterdam from 1987-1992. They reported positive associations between daily total mortality and the daily mean concentrations of particles with a $50 \%$ cut-off aerodynamic diameter of $10 \mu \mathrm{m}$ (PM10), black smoke (BS) and ozone $\left(\mathrm{O}_{3}\right)$, but not with carbon monoxide $(\mathrm{CO})$ or sulphur dioxide $\left(\mathrm{SO}_{2}\right)$. HoEK et al. [2] studied the association between fluctuations in daily mortality and daily levels of ambient air pollution for the city of Rotterdam from 1983-1991. They reported positive associations between daily total mortality and the daily mean concentrations of total suspended particles (TSP), BS and $\mathrm{O}_{3}$, but not with $\mathrm{CO}$ or $\mathrm{SO}_{2}$. MACKENBACH et al. [3] studied the association between daily mortality and $\mathrm{SO}_{2}$ levels in the Netherlands from 1979-1987. After adjustment for a number of potential confounding factors, no association was found between levels of $\mathrm{SO}_{2}$ and mortality.

The Air Pollution on Health: a European Approach (APHEA) study has also been conducted in the Netherlands [4]. In Amsterdam (694,700 inhabitants) and Rotterdam (576,200 inhabitants), $\mathrm{O}_{3}$ had a nonsignificant positive effect on the number of respiratory emergency admissions in summer in people aged $\geqslant 65 \mathrm{yrs}$ (relative risk (RR) for a $100 \mu \mathrm{g} \cdot \mathrm{m}^{-3}$ increase in $\mathrm{O}_{3}-8 \mathrm{~h}$ of 1.123 in Amsterdam and a significant positive effect of 1.34 in Rotterdam (1977-1981)). $\mathrm{SO}_{2}$ did not show any clear effects; in Amsterdam a significant negative effect was even found. The same was true for nitrogen dioxide $\left(\mathrm{NO}_{2}\right)$ in Amsterdam; in Rotterdam, however, $\mathrm{NO}_{2}$ showed nonsignificant positive effects (RR 0.97 and 1.3 respectively). BS did not show any clear effects in Amsterdam; in Rotterdam it was positively but not significantly related to the number of admissions. The results show that the relationship between short-term air pollution and emergency hospital admissions is not always consistent at these rather low levels of daily hospital admissions and of air pollution.

In another time-series study in the Netherlands, a strong association between the day-to-day variation in pollen concentrations and that of deaths due to cardiovascular disease, chronic obstructive pulmonary disease (COPD), and pneumonia was found [5].

The association of daily mortality with short-term variations in the ambient concentrations of major gaseous pollutants and particulate matter (PM) in the four major Dutch urban areas was compared with that in the remainder of the country [6]. Daily mortality was significantly associated with the concentration of all air pollutants. An increase in the PM10 concentration by $100 \mu \mathrm{g} \cdot \mathrm{m}^{-3}$ was associated with a RR of 1.02 for total mortality. The largest RR were found for pneumonia deaths. Ozone had the most consistent, independent association with mortality. Aerosol sulphate $\left(\mathrm{SO}_{4}{ }^{2-}\right)$, nitrate $\left(\mathrm{NO}_{3-}\right)^{-}$, and BS were more consistently associated with total mortality 
than was PM10. The RR for all pollutants were substantially larger in the summer months than in the winter months. The RR of total mortality for PM10 was 1.10 for the summer and 1.03 for the winter. There was no consistent difference between $\mathrm{RR}$ in the four major urban areas and the more rural areas.

Further, deaths due to heart failure, arrhythmia, cerebrovascular causes, and thrombocytic causes were more strongly associated with air pollution than cardiovascular deaths in general [7]. Heart failure deaths, which made up $10 \%$ of all cardiovascular deaths, were found to be responsible for $\sim 30 \%$ of the cardiovascular deaths related to $\mathrm{PM}, \mathrm{SO}_{2}, \mathrm{CO}$, and $\mathrm{NO}_{2}$.

Since exposure to ambient air pollution has been estimated mostly as city average concentrations, assuming homogeneous exposure within the city, HoEK et al. [8] used an ongoing cohort study, the Netherlands Cohort Study (NLCS) on diet and cancer, to investigate the relationship between trafficrelated air pollution and mortality, based on developing methods for exposure assessment and evaluating the contrast in exposure to air pollution within the cohort. Distance to major roads was calculated to characterise local traffic contributions, using a Geographic Information System (GIS). Interpolation resulted in reasonably precise regional background estimation. Urban and local scales contributed significantly to the contrast within the cohort, supporting the use of the estimated concentration at the 1986 address as a relevant exposure variable.

Recently, the results of the analyses of the relationship between mortality and the estimated concentration at the 1986 address were published by HoEK et al. [9]. They investigated a random sample of 5,000 people from the full cohort of the NLCS study (age 55-69 yrs) from 1986-1994. The association between exposure to air pollution and (cause specific) mortality was assessed with Cox's proportional hazards models, with adjustment for potential confounders. Four hundred and eighty-nine $(11 \%)$ of 4,492 people with data died during the follow-up period. Cardiopulmonary mortality was associated with living near a major road (RR 1.95 (95\% confidence interval (CI) 1.09-3.52)) and, less consistently, with the estimated ambient background concentration (RR 1.34 (95\% CI 0.68-2.64)). The $\mathrm{RR}$ for living near a major road was 1.41 (95\% CI $0.94-2.12)$ for total deaths. Noncardiopulmonary, nonlung cancer deaths were unrelated to air pollution (RR 1.03 (95\% CI 0.54-1.96) for living near a major road).

\section{Background: studies on air pollution effects among the elderly}

Numerous studies have shown associations between daily variations in air pollution and daily mortality [10-15]. Initially these studies were conducted in the USA, but more recently studies have been conducted in Europe and other parts of the world. Some studies have explored the age-specific associations between daily variations in air pollution and mortality, especially in the elderly population that is assumed to be more vulnerable to air pollution effects than the general population [16]. Higher risks of particulate matter for deaths $>65 \mathrm{yrs}$ have been reported before in Philadelphia [17], Cincinnati [18], Amsterdam [1], Mexico City [19], Montreal [20] and Sao Paulo [21]. In a study in Rotterdam [2] TSP and especially $\mathrm{O}_{3}$ RRs were substantially larger for deaths $>78$ yrs, the median age of death. In a study in six American cities, RR of PM2.5 (particles with a 50\% cut-off aerodynamic diameter of $2.5 \mu \mathrm{m}$ ) exposure for subjects $>65$ yrs was only slightly higher than for the total population [22]. SUNYER et al. [23] in Barcelona and PRESCOTT et al. [24] in Edinburgh, found generally the same effect sizes in mortality effects of air pollution between older and younger age groups.

Thus, it seems from the existing literature that overall the elderly population seem to be at a slightly higher mortality risk for air pollution. Furthermore, it remains unclear whether elderly people are more sensitive to specific components in the air pollution mixture, although some of the studies suggest that particulate air pollution is most consistently associated with higher RR in the elderly.

\section{Aim}

Since information on age-specific and pollutant-specific RR is scarce and not yet clarified, the present authors evaluated the association between daily air pollution and daily mortality in the Netherlands for the period 1986-1994 [2] and, as a part of the study investigated whether the magnitude of the effect of air pollution depended on the age at death. Detailed information on the general study is given in HoEK et al. [6]. In this paper the age-specific analyses are described.

The aims of the analyses were: 1) to quantitate the agespecific associations between daily excess mortality and exposure to particulate matter, $\mathrm{SO}_{2}, \mathrm{CO}, \mathrm{O}_{3}$, and $\mathrm{NO}_{2}$ for the Dutch population, based on observed data from 1986-1994; and 2) to test differences in the age-specific associations between specific causes of death (cause specific mortality data), and between pollutants.

\section{Methods}

Mortality data for the whole of the Netherlands were obtained from the Central Bureau of Statistics (CBS) for the period 1986-1994. In January 1989 the total Dutch population counted 14.8 million people. Individuals who died due to external causes and infants $<1$-month old were excluded. For the analyses, total mortality, death counts from pneumonia (International Classification of Diseases (ICD)-9 480-486), chronic obstructive lung disease (ICD-9 490-496) and cardiovascular diseases (ICD-9 390-448) were selected.

Daily air quality data were obtained from 16 sites of the National Ambient Air Quality Monitoring Network (RIVM). Only population-oriented monitoring sites were selected where PM10 and/or BS was measured. In addition to daily mean data on PM10 and BS, daily mean data on the gaseous pollutants $\mathrm{NO}_{2}, \mathrm{SO}_{2}, \mathrm{CO}$, and $8 \mathrm{~h}$ mean data on $\mathrm{O}_{3}$ were used.

Hourly data on temperature and relative humidity were obtained from the national network of the Royal Dutch Meteorological Institute. Data on weekly incidence of influenzatype illnesses were obtained from the Dutch Institute of Primary Health Care.

\section{Data analyses}

The relationship between daily mortality and air pollution was modelled using Poisson regression analysis. All pollution/ mortality associations were adjusted for potential confounding due to long-term trends, seasonal trends, influenza epidemics, ambient temperature, ambient relative humidity, day of the week and holidays, using generalised additive models with locally weighted regression (LOESS) smoothing as described before $[2,6]$. The single-day air pollution concentrations with lags 1 day for $\mathrm{O}_{3}$ and the weekly average concentration for other pollutants (average of lags 0-6 days) were used in the statistical analyses. These were the lags that correlated best in 
Table 1.-Median (50th percentile) total, cardiovascular (CVD), chronic obstructive pulmonary diseases (COPD) and pneumonia daily mortality in the Netherlands (1986-1994) per age class (counts·day ${ }^{-1}$ )

\begin{tabular}{lrrrc}
\hline Age & Total & CVD & COPD & Pneumonia \\
\hline$<45$ & 12 & 2 & 0 & 0 \\
$45-64$ & 50 & 17 & 1 & 0 \\
$65-74$ & 74 & 31 & 4 & 1 \\
$\geqslant 75$ & 192 & 90 & 10 & 8 \\
\hline
\end{tabular}

the all age analyses. Final models were checked using the partial autocorrelation function of the residuals and plots of the residuals of the model versus date, temperature, influenza and relative humidity. Sensitivity analyses were conducted by examination of the impact of excluding days with very high concentrations; using less or more days for the smoothed date variable used for adjusting for seasonal trends; excluding days with the highest influenza counts; excluding the lowest and highest daily average temperatures; excluding relative humidity from the model. Age-specific analyses were performed for the age classes $<45,45-64,65-74$ and $\geqslant 75$ yrs. For presentation RRs were calculated for rounded differences between the 1st and 99th percentile of the air pollution variable. The ranges used were 80 for $\mathrm{PM} 10 ; 40$ for $\mathrm{BS}$ and $\mathrm{SO}_{2} ; 30$ for $\mathrm{NO}_{2}$; 150 for $\mathrm{O}_{3}$ and 1,200 for $\mathrm{CO}$, all in $\mu \mathrm{g} \cdot \mathrm{m}^{-3}$.

\section{Results}

On average, per day 330 persons died in the Netherlands. In table 1 the median daily mortality per age class is presented. As can be seen from the table daily death counts due to COPD and pneumonia were small, especially in the younger age classes.

The distribution of the daily air pollution concentrations, weather and influenza counts is presented in table 2. Air pollution levels during the study period were comparable with levels found elsewhere in Western Europe. The correlations between $\mathrm{PM} 10, \mathrm{BS}, \mathrm{SO}_{2}, \mathrm{NO}_{2}$ and $\mathrm{CO}$ were relatively high $(0.6-0.9)$ indicating that it is difficult to separate the independent effects of these pollutants. Ozone had a small negative correlation with all other pollutants.

In figure 1 and table 3 the results of the mortality-air pollution analysis are presented. Statistically significant associations were mostly found in the elderly, that is the age categories of 65-74 and $\geqslant 75$ yrs for the pollutants PM10, BS,
Table 2. - Distribution (median, minimum, maximum) of the daily air pollution concentrations, weather and influenza counts in the Netherlands in the period 1986-1994

\begin{tabular}{|c|c|c|c|}
\hline & Median & Min & Max \\
\hline \multicolumn{4}{|l|}{ Air pollution concentrations $\mu \mathrm{g} \cdot \mathrm{m}^{-3}$} \\
\hline PM10 & 34 & 10 & 278 \\
\hline BS & 10 & 1 & 120 \\
\hline $\mathrm{O}_{3}$ & 47 & 1 & 226 \\
\hline $\mathrm{NO}_{2}$ & 32 & 8 & 106 \\
\hline $\mathrm{SO}_{2}$ & 10 & 1 & 247 \\
\hline $\mathrm{CO}$ & 406 & 174 & 2620 \\
\hline Temperature ${ }^{\circ} \mathrm{C}$ & 10 & -13 & 26 \\
\hline Relative humidity \% & 84 & 44 & 100 \\
\hline $\begin{array}{l}\text { Influenza counts } \text { week }^{-1} \text { per } 10,000 \\
\text { inhabitants }\end{array}$ & 4 & 0 & 71 \\
\hline
\end{tabular}

PM10: particles with a $50 \%$ cut-off aerodynamic diameter of $10 \mu \mathrm{M}$; BS: black smoke; $\mathrm{O}_{3}$ : ozone; $\mathrm{NO}_{2}$ : nitrogen dioxide; $\mathrm{SO}_{2}$ : sulphur dioxide; $\mathrm{CO}$ : carbon monoxide.

$\mathrm{SO}_{2}, \mathrm{NO}_{2}$ and $\mathrm{CO}$. This is probably at least partly a reflection of the better precision of RR estimates due to the larger numbers of deaths in these age groups. Statistically significant associations for the age categories $<65$ yrs were found for $\mathrm{O}_{3}$ (total and COPD mortality), PM10 (pneumonia), $\mathrm{NO}_{2}$ (pneumonia) and $\mathrm{CO}$ (pneumonia).

RR estimates for deaths between 45-65 yrs tended to be smaller than RRs for deaths $>65$ yrs, with the exception of $\mathrm{O}_{3}$.

For cardiovascular mortality the RR for PM10, $\mathrm{O}_{3}$ and $\mathrm{CO}$ of the latter age group were similar to the RR for deaths $>65$ yrs. Particulate matter air pollution (PM10 and BS) was not more consistently associated with mortality than were the gaseous pollutants.

Table 3 shows that larger RRs for air pollution were mostly found in the elderly group, with some exceptions for $\mathrm{O}_{3}$ and pneumonia respectively.

\section{Discussion}

In the Netherlands short-term fluctuations of daily mortality were associated with short-term fluctuations in concentrations of all pollutants, both particulate and gaseous. For PM10, an overall RR of 1.02 for $100 \mu \mathrm{g} \cdot \mathrm{m}^{-3}$ PM10 (95\% CI $\left.1.00-1.03\right)$ was found, which is comparable with recent estimates from the USA and the APHEA project. Age-specific analyses showed

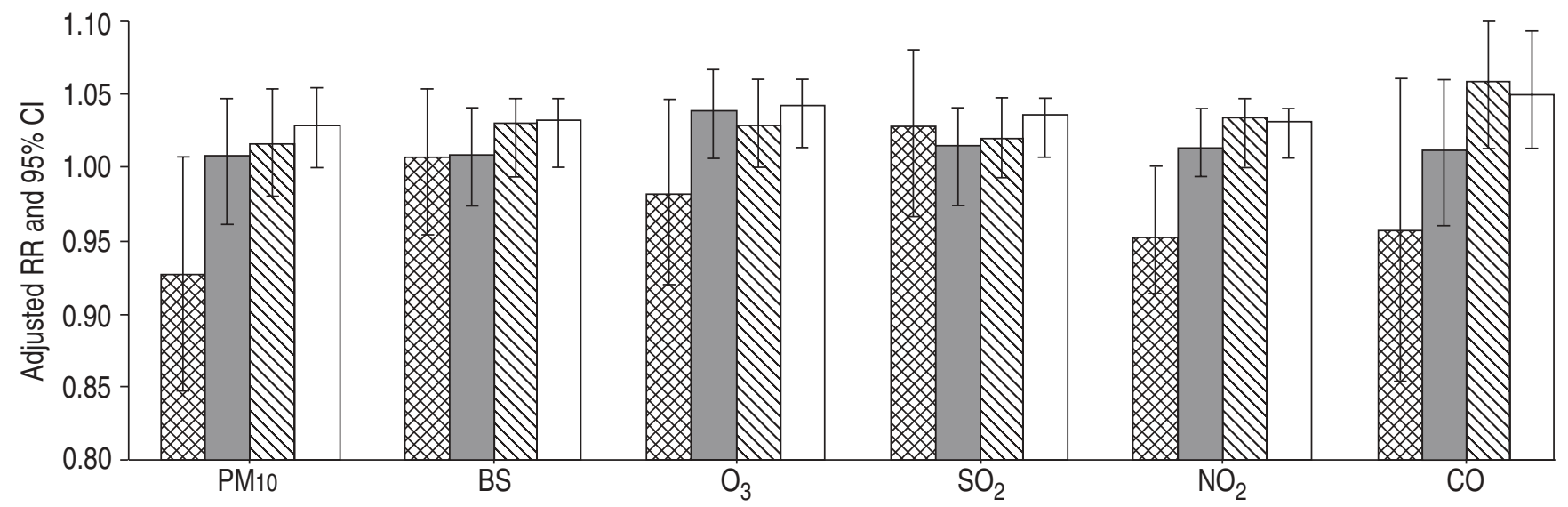

Fig. 1.-Association between air pollution and total mortality. Age classes: $<45 \mathrm{yrs} ; \square: 45-64 \mathrm{yrs} ; \mathbb{\mathbb { N } :} 65-74 \mathrm{yrs} ; \square: \geqslant 75 \mathrm{yrs}$. 
Table 3. - Association between air pollution and specific diseases

\begin{tabular}{lcccc}
\hline Pollutant & Age class & Cardiovascular & COPD & Pneumonia \\
\hline PM10 & $<45$ & $0.906(0.728-1.128)$ & $1.153(0.587-2.268)$ & $1.427(0.806-2.525)$ \\
& $45-64$ & $1.023(0.945-1.106)$ & $1.139(0.841-1.541)$ & $1.712(1.042-2.815)$ \\
& $65-74$ & $1.002(0.945-1.062)$ & $1.166(0.991-1.372)$ & $1.240(0.879-1.748)$ \\
$\mathrm{BS}$ & $\geqslant 75$ & $1.016(0.981-1.052)$ & $1.066(0.965-1.178)$ & $1.123(1.011-1.247)$ \\
& $<45$ & $1.057(0.934-1.196)$ & $0.872(0.599-1.270)$ & $0.741(0.519-1.057)$ \\
& $45-64$ & $1.000(0.957-1.046)$ & $1.025(0.870-1.209)$ & $1.264(0.934-1.711)$ \\
$\mathrm{O}_{3}$ & $65-74$ & $1.040(1.006-1.075)$ & $1.204(1.095-1.324)$ & $0.951(0.767-1.179)$ \\
& $\geqslant 75$ & $1.030(1.010-1.051)$ & $1.012(0.957-1.070)$ & $1.123(1.055-1.196)$ \\
& $<45$ & $1.022(0.863-1.212)$ & $2.137(1.258-3.630)$ & $1.142(0.682-1.911)$ \\
$\mathrm{SO}_{2}$ & $45-64$ & $1.038(0.977-1.103)$ & $1.083(0.856-1.371)$ & $0.677(0.424-1.081)$ \\
& $65-74$ & $1.005(0.960-1.053)$ & $0.989(0.862-1.135)$ & $1.597(1.164-2.190)$ \\
& $\geqslant 75$ & $1.073(1.044-1.102)$ & $0.996(0.919-1.079)$ & $1.367(1.245-1.501)$ \\
$\mathrm{NO}_{2}$ & $<45$ & $1.060(0.937-1.200)$ & $0.737(0.490-1.108)$ & $0.708(0.482-1.038)$ \\
& $45-64$ & $0.993(0.949-1.038)$ & $0.915(0.771-1.087)$ & $0.946(0.682-1.311)$ \\
& $65-74$ & $1.023(0.989-1.059)$ & $1.137(1.032-1.251)$ & $0.860(0.678-1.089)$ \\
$\mathrm{CO}$ & $\geqslant 75$ & $1.039(1.018-1.060)$ & $1.026(0.967-1.089)$ & $1.099(1.028-1.175)$ \\
& $<45$ & $0.990(0.897-1.094)$ & $0.818(0.610-1.097)$ & $0.865(0.650-1.151)$ \\
& $45-64$ & $0.997(0.962-1.033)$ & $1.053(0.920-1.205)$ & $1.406(1.092-1.810)$ \\
& $65-74$ & $1.034(1.007-1.063)$ & $1.173(1.085-1.268)$ & $1.067(0.897-1.269)$ \\
& 275 & $1.027(1.011-1.044)$ & $1.046(1.000-1.094)$ & $1.129(1.072-1.188)$ \\
\hline
\end{tabular}

Data are presented as adjusted relative risk (95\% confidence intervals). COPD: chronic obstructive pulmonary disease; PM10: particles with a $50 \%$ cut-off aerodynamic diameter of $10 \mu \mathrm{M}$; BS: black smoke; $\mathrm{O}_{3}$ : ozone; $\mathrm{NO}_{2}$ : nitrogen dioxide; $\mathrm{SO}_{2}$ : sulphur dioxide; $\mathrm{CO}$ : carbon monoxide.

that statistically significant associations between air pollution and mortality were mostly found in the elderly ( $>65 \mathrm{yrs}$ ) and that the RR for deaths $<65$ yrs were generally smaller than in the older age classes. Exceptions were the associations between $\mathrm{O}_{3}$ and COPD in the younger ages and between air pollution and pneumonia deaths which showed high RR in the age group 45-64 yrs, suggesting that for some death causes (pneumonia) younger age groups seem to be at risk too. Both particulate matter and gaseous components were associated with statistically significant mortality effects in the elderly age groups indicating no preference for a specific air pollutant in the mortality associations.

Higher RRs of particulate matter for deaths in the $>64-\mathrm{yr}$ age group have been found in Philadelphia (RR for $100 \mu \mathrm{g} \cdot \mathrm{m}^{-3}$ TSP: $1.10(95 \%$ CI 1.06-1.13) in the $\geqslant 65$ yr age group versus $1.03(1.03-1.10)$ in the $<65 \mathrm{yr}$ age group) [17], Cincinnati (RR for $100 \mu \mathrm{g} \cdot \mathrm{m}^{-3}$ TSP: $1.09(95 \%$ CI $1.05-1.14)$ in the $>64 \mathrm{yr}$ age group versus 1.06 (1.03-1.10) in all ages) [18] and Amsterdam (RR for $100 \mu \mathrm{g} \cdot \mathrm{m}^{-3} \mathrm{BS}$ : $1.26(95 \%$ CI $1.07-1.49)$ in the $>64 \mathrm{yr}$ age group versus $1.19(1.02-1.38)$ in all ages; and RR for $100 \mu \mathrm{g} \cdot \mathrm{m}^{-3}$ PM10: 1.07 (95\% CI 0.98-1.16) in the $>64 \mathrm{yr}$ age group versus $1.06(0.99-1.14)$ in all ages) [1], and more recently in Montreal (RR for $12.5 \mu \mathrm{g} \cdot \mathrm{m}^{-3}$ PM2.5: $1.03(95 \%$ CI 1.02-1.04) in the $\geqslant 64$ yr age group versus $1.01(0.99-1.03)$ in $<65 \mathrm{yr}$ age group) [20]. For Rotterdam, TSP and especially $\mathrm{O}_{3}$ RRs were substantially larger for deaths $<78 \mathrm{yrs}$, the median age at death (RR for $91 \mu \mathrm{g} \cdot \mathrm{m}^{-3} \mathrm{TSP}: 1.06(95 \% \mathrm{CI}$ $1.01-1.11)$ in the $>78 \mathrm{yr}$ age group versus $1.04(0.99-1.10)$ in the $<78 \mathrm{yr}$ age group; RR for $67 \mu \mathrm{g} \cdot \mathrm{m}^{-3} \mathrm{O}_{3}: 1.13(95 \% \mathrm{CI}$ $1.06-1.20)$ in the $>78$ yr age group versus 1.0 in the $<78 \mathrm{yr}$ age group [2]. In six cities in the USA [22] an increase in daily total mortality of $1.5 \%$ per $10 \mu \mathrm{g} \cdot \mathrm{m}^{-3} \mathrm{PM} 2.5$ was found in the total population and a slightly increased mortality of $1.7 \%$ in the elderly ( $\geqslant 65 \mathrm{yrs})$.

PRESCOTT et al. [24] found generally equal effect sizes in mortality effects of air pollution between the two age groups $(<65 \mathrm{yrs}, \geqslant 65 \mathrm{yrs})$, but in the people aged $\geqslant 65 \mathrm{yrs}$, daily all-cause mortality and respiratory mortality had statistically significant association with BS. For other air pollution components $\left(\mathrm{SO}_{2}, \mathrm{PM} 10, \mathrm{NO}_{2}, \mathrm{O}_{3}\right.$ and $\left.\mathrm{CO}\right)$ no significant associations were found with all cause, cardiovascular or respiratory causes mortality. BORJA-Aburto et al. [19] also found somewhat larger excesses of death among people $>65$ yrs in Mexico City in association with PM2.5 levels, but for other components $\left(\mathrm{O}_{3}\right.$, $\mathrm{NO}_{2}$ ) this was not the case. Gouveia and FleTCHER [21] in Sao Paulo, Brazil, showed that older age groups seemed to be at higher risks of mortality associated with air pollution. While total causes mortality was significantly associated with air pollution in the age group $>65$ yrs, no significant effects of air pollution were observed for $<65$-yr age groups, although for most of the air pollution components that were analysed, an RR above unity was observed. An increase in total mortality of $5 \%$ and $17 \%$ for a $100 \mu \mathrm{g} \cdot \mathrm{m}^{-3}$ increase in PM10 and $\mathrm{SO}_{2}$ respectively was found in the elderly group compared to $1 \%$ and $5 \%$ in the younger age group. GoLDBERG et al. [20] in a study in Montreal, Quebec, also found higher excesses in daily mortality for persons 65-yrs-old for daily variations in several measures of particulate air pollution. In general the estimated mean percentage change in daily nonaccidental mortality for an increase in levels of pollution across the interquartile range differed between $1-2 \%$ depending on the exposure measure selected [20].

In the current study associations were not only found for particulate air pollutants, but also for gaseous air pollutants. This is partly caused by the high co-linearity between the pollutants. However, in two pollutant models (not presented) RR estimates for gases remained significant [2, 6], suggesting that factors other than particle indicators for the air pollution mixture are important as well. For a $100 \mu \mathrm{g} \cdot \mathrm{m}^{-3}$ increase in PM10 there was a nonsignificant increase in total mortality of $1 \%$ for the younger age categories $(<65$ yrs $)$ compared to a significant increase in daily mortality of $2-3 \%$ in the elderly $(\geqslant 65 \mathrm{yrs})$. This is in the order of the effect sizes found by GOUVEIA and FletCHER [21] and GOLDBERG and coworkers 
[20, 25], and in agreement with other studies. The present authors' results from the analyses of the gaseous components showed statistically significant associations with total and causespecific mortality indicating that other factors than particulate matter that are causally associated with mortality cannot be excluded. The current authors do not interpret the associations found for the gaseous pollutants $\mathrm{SO}_{2}$ and $\mathrm{NO}_{2}$ at the concentration levels in the Netherlands as causal [26].

To conclude, overall, the elderly ( $>65$ yrs) are at higher risk for acute mortality effects of air pollution compared to younger age groups.

\section{References}

1. Verhoeff AP, Hoek G, Schwartz J, van Wijnen JH. Air pollution and daily mortality in Amsterdam. Epidemiol 1996; 7: 225-230.

2. Hoek G, Schwartz JD, Groot B, Eilers P. Effects of ambient particulate matter and ozone on daily mortality in Rotterdam, the Netherlands. Archiv Environ Health 1997; 52: 455-463.

3. Mackenbach JP, Looman CWN, Kunst AE. Air pollution, lagged effects of temperature, and mortality: the Netherlands 1979-87. J Epidemiol Comm Health 1993; 47: 121-126.

4. Schouten JP, Vonk JM, de Graaf A. Short term effects of air pollution on emergency hospital admissions for respiratory disease: results of the APHEA project in two major cities in The Netherlands, 1977-89. J Epidemiol Community Health 1996; 50: Suppl. 1, S22-S29.

5. Brunekreef B, Hoek G, Fischer P, Spieksma FT. Relation between airborne pollen concentrations and daily cardiovascular and respiratory-disease mortality. Lancet 2000; 355: $1517-1518$.

6. Hoek G, Brunekreef B, Verhoeff A, van Wijnen J, Fischer P. Daily mortality and air pollution in The Netherlands. $J$ Air Waste Manag Assoc 2000; 50: 1380-1389.

7. Hoek G, Brunekreef B, Fischer P, van Wijnen J. The association between air pollution and heart failure, arrhythmia, embolism, thrombosis, and other cardiovascular causes of death in a time series study. Epidemiology 2001; 12: 355-357.

8. Hoek G, Fischer P, Van Den Brandt P, Goldbohm S, Brunekreef B. Estimation of long-term average exposure to outdoor air pollution for a cohort study on mortality. $J$ Expo Anal Environ Epidemiol 2001; 11: 459-469.

9. Hoek G, Brunekreef, Goldbohm S, Fischer P, van den Brandt PA. Association between mortality and indicators of traffic-related air pollution in the Netherlands: a cohort study. Lancet 2002; 360: 1203-1209.

10. Dockery DW, Pope CA III. Acute respiratory effects of particulate air pollution. Ann Rev Public Health 1994; 15: 107-132.
11. Schwartz J. Air Pollution and Daily Mortality: a review and meta-analysis. Environ Res 1994; 64: 36-52.

12. Brunekreef B, Dockery DW, Krzyzanowski M. Epidemiologic studies on short-term effects of low levels of major ambient air pollution components. Environ Health Perspect 1995; 103: Suppl. 2, 3-13.

13. Thurston GD. A critical review of PM10 mortality tine-series studies. J Expos Anal Environ Epidemiol 1996; 6: 3-21.

14. Vedal S. Ambient particles and health: lines that divide. $J$ Air \& Waste Manage Assoc 1997; 47: 551-581.

15. Katsouyanni K, Touloumi G, Spix C, et al. Short-term effects of ambient sulphur dioxide and particulate matter on mortality in 12 European cities: results from time-series data from the APHEA Project. Brit Med J 1997; 314: 1658-1663.

16. Abercrombie GF. December fog in London and the Emergency Bed Service. Lancet: 1953: 234-235.

17. Schwartz J, Dockery DW. Increased mortality in Philadelphia associated with daily air pollution concentrations. Am Rev Respir Dis 1992; 145: 600-604.

18. Schwartz J. Total suspended particulate matter and daily mortality in Cincinnati, Ohio. Environ Health Perspect 1994; 102: 186-189.

19. Borja-Aburto VH, Castillejos M, Gold DR, Bierzwinski S, Loomis D. Mortality and ambient fine particles in Southwest Mexico City, 1993-1995. Environ Health Perspect 1998; 12: 849-855.

20. Goldberg MS, Burnett RT, Bailar JC 3rd, et al. The association between daily mortality and ambient air particle pollution in Montreal, Quebec. 1. Nonaccidental mortality. Environ Res 2001; 86: 12-25.

21. Gouveia N, Fletcher T. Time series analysis of air pollution and mortality: effects by cause, age and socio-economic status. J Epidemiol Community Health 2000; 54: 750-755.

22. Schwartz J, Dockery DW, Neas LM. Is daily mortality associated specifically with fine particles? Air \& Waste Manage Assoc 1996; 46: 927-939.

23. Sunyer J, Castellsague J, Saez M, Tobias A, Anto JM. Air pollution and mortality in Barcelona. $J$ Epidemiol Comm Health 1996; 50: Suppl. 1, S76-S80.

24. Prescott GJ, Cohen GR, Elton RA, Fowkes FGR, Agius RM. Urban air pollution and cardiopulmonary ill health: a 14.5 year time series study. Occup Environ Med 1998; 55: 697-704.

25. Goldberg MS, Bailar III JC, Burnett RT et al. Identifying subgroups of the general population that may be susceptible to short-term increases in particulate air pollution: a timeseries study in Montreal, Quebec. Health Effects Institute, Report nr. 97. Boston, MA, Health Effects Institute, 2000.

26. Buringh E, Fischer P, Hoek G. Is $\mathrm{SO}_{2}$ a causative factor for the PM associated mortality risks in the Netherlands? Inhalation Toxicology 2000; 12: Suppl. 1, 55-60. 